\title{
PELAKSANAAN HAJI DAN UMRAH BAGI GOLONGAN KHUNTHA DAN MUKHANNATH
}

\section{Implementation of the Hajj and Umraa for the Hermaphrodites (Khuntha) and Transvestites (Mukhannath)}

\author{
Razali Shahabudin * \\ Anisah Ab Ghani **
}

\begin{abstract}
Gender disorder is one of the factors causing the occurrence of difficulties in implementing obligatory worships such as prayers and the hajj. In this context, the question that often arises is whether that person should be in accordance with the behavior of a man or a woman. The same problem is also faced by individuals who are classified as hermaphrodites (khuntha). This article explains the issues arising in the practice of the hajj and umraa for hermaphrodites and those who suffer from gender disorders. It also proposes a solution to the above problems. This article is a qualitative and library mode research and related data have been analyzed. The article concludes that hermaphrodites shall follow the rules of a woman in performing the hajj and umraa. For the born or intentional transvestites (mukhannath), whether he has or has not undergone sexual transplant operations, or has gone sexual transplant operations without sound syariah ruling, he should follow his or her original sex in observing ritual worships including the hajj and umraa.
\end{abstract}

Keywords: Khuntha, Mukhannath, Worship, Hajj,Umraa

* Ahli Jawatankuasa Penasihat Ibadat Haji (TH - JAKIM).

** Ahli Jawatankuasa Penasihat Ibadat Haji (TH - JAKIM). 


\section{PENDAHULUAN}

Istilah khunsa, berasal dari perkataan Arab خنث yang bererti lembut. ${ }^{1}$ Menurut Kamus Dewan, khuntha diertikan sebagai orang yang mempunyai dua alat kelamin. ${ }^{2}$ Golongan istimewa ini diciptakan Allah SWT sebagai sebahagian daripada bukti kekuasaan Allah SWT kerana mereka mempunyai ciri fizikal dan naluri yang istimewa sejak lahir.

\section{KHUNTHA MENURUT SYARAK}

Islam memperakui kewujudan golongan dalam masyarakat yang dipanggil khuntha (hermaphrodite) iaitu seseorang yang mempunyai kedua-dua alat kelamin lelaki dan perempuan.

Ulama fiqh membahagikan khuntha kepada dua: khuntha ghayr musykil (wädih) dan khuntha musykil. Khuntha ghayr musykil (wädih) ialah khuntha yang nyata memiliki tanda-tanda kelelakian atau keperempuanan dan dapat dibezakan sama ada lelaki atau perempuan semasa bayi oleh warisnya melalui pemerhatian sifat dan ciri alat kelamin tersebut. Ia juga dikenalpasti berdasarkan dari alat kelamin yang mana satu tempat keluar air kencing terlebih dahulu. Pada dasarnya jantina khuntha dapat dikenalpasti dengan jelas berdasarkan yang mana alat yang lebih dominan berbanding dengan yang satu lagi yang kurang berfungsi. ${ }^{3}$

Manakala khuntha musykil ialah individu yang tidak diketahui langsung jantinanya disebabkan tiada sebarang tanda-tanda yang boleh diklasifikasikan sebagai lelaki ataupun perempuan. Individu ini juga mempunyai dua alat kelamin. Air kencingnya keluar serentak dari kedua-dua alat tersebut dan identiti jantinanya sukar dibezakan atau hanya dapat dibezakan setelah baligh. ${ }^{4}$

Fu'ād Ifram al-Bustan̄̄, Munjib al-Ṭulāb (Bayrūt: Dār al-Musyriq, t. t.), 180 .

2 Dewan Bahasa dan Pustaka, Kamus Dewan Edisi Empat (Kuala Lumpur: Dewan Bahasa dan Pustaka, 2007), 784.

3 Ibn Qudāmah, al-Mughnī wa al-Syarh al-Kab̄̄r (t. t.: Dār al-Kitāb al-'Arabī, t. t.), 7:114-115.

4 Wahbah al-Zuhaylī, al-Fiqh al-Islāmī wa Adillatuh (Damsyiq: Dār al-Fikr, 1997), 10:7900. 
Musykil ini hilang apabila dapat ditentukan dari mana tempat mula keluar air kencing atau kuantiti yang paling banyak atau dikira yang paling akhir berhenti. Jantina mereka juga boleh ditentukan setelah baligh dengan tanda-tanda yang dikenal pasti sama ada memiliki ciri-ciri kewanitaan (seperti kedatangan haid) atau kelelakian (seperti tumbuh janggut dan misai). ${ }^{5}$

Di sini dapatlah dikatakan bahawa faktor tempat air kencing keluar (banyak atau sikit, yang mana paling akhir berhenti) merupakan tanda umum bagi menentukan individu khunsa sama ada lelaki atau perempuan. Tetapi apabila anggota kelamin lelaki atau perempuan mengeluarkan air kencing serentak atau tidak dapat ditentukan kuantiti maka ia dianggap khunsa musykil.

\section{PENENTUAN JANTINA DARI ASPEK PERUBATAN ${ }^{6}$}

Menurut ilmu perubatan, cara menentukan sama ada seseorang individu itu lelaki atau perempuan adalah merujuk kepada jantina biologi dirinya. Faktor biologi seseorang ditentukan melalui tiga perkara iaitu:-

1. faktor kromosom;

2. kehadiran 'gonads' (ovari - rahim/ uterus bagi perempuan dan testes - kerandut buah zakar bagi lelaki) dan

3. bentuk alat kelamin seseorang itu semasa dilahirkan - sama ada terdapat 'kecacatan' atau tidak.

Kecelaruan jantina berlaku apabila bayi yang dilahirkan mempunyai kedua-dua alat kelamin (hermaphrodite) atau alat kelamin yang tidak jelas. Dalam istilah perubatan ini dipanggil ambiguous genitalia (ketidakpastian alat kelamin).

Ibn Qudāmah, al-Mughnī, 7:620.

6 Timothy G. Canty, "The Child with Ambiguous Genitalia: A Neonatal Surgical Emergency," in Ann Surg 186 (3) 1977, 272-279. Lihat juga Al-Mutair A, Iqbal MA, Sakati N, Ashwal A, "Cytogenetics and Etiology of Ambiguous Genitalia in 120 Pediatric Patients" Ann Saudi Med. 2004 Sep-Oct; 24(5):368-72. U.S. National Library of Medicine, "Ambiguous Genitalia" http://www.nlm.nih.gov/ medlineplus/ency/article/003269.htm, diakses pada 2 Januari 2012. 
Kod genetik bagi jantina seseorang individu ditentukan semasa peringkat awal persenyawaan. Ovum daripada si ibu mengandungi kromosom $X$, manakala sel sperma si bapa mengandungi sama ada kromosom X atau Y. Kromosom X atau Y ini akan menentukan jantina genetik bagi seseorang anak.

Kebiasaannya, seseorang anak akan mewarisi sepasang kromosom - iaitu satu X daripada ibunya, dan satu X atau satu $\mathrm{Y}$ daripada bapanya. Anak yang mewarisi kromosom $\mathrm{X}$ daripada bapanya adalah genetik perempuan (dua kromosom X). Anak yang mewarisi kromosom $\mathrm{Y}$ daripada bapanya adalah genetik lelaki (satu kromosom X dan satu kromosom Y).

Organ pembiakan serta alat kelamin bagi lelaki dan perempuan terhasil daripada tisu yang sama pada fetus. Sekiranya proses pertukaran tisu ini kepada 'lelaki' atau 'perempuan' terganggu, ambiguous genitalia akan terbentuk. Contohnya, individu yang memiliki kod genetik lelaki akan memiliki sifat luaran seorang perempuan normal. Ataupun, individu yang memilikki kod genetik perempuan akan memiliki sifat luaran seorang lelaki normal. ${ }^{7}$

Dalam rajah 1 di bawah menunjukkan contoh gambar bagi masalah kecelaruan jantina atau ketidakpastian jantina (ambiguous genetalia) dan perbezaan alat kelamin normal manakala rajah 2 menunjukkan gambar sebenar bagi kes ambiguous genetalia yang mempunyai kedua-dua alat kelamin lelaki dan perempuan.

Rajah 1: Perbezaan ambiguous genetalia dengan alat kelamin normal $^{8}$

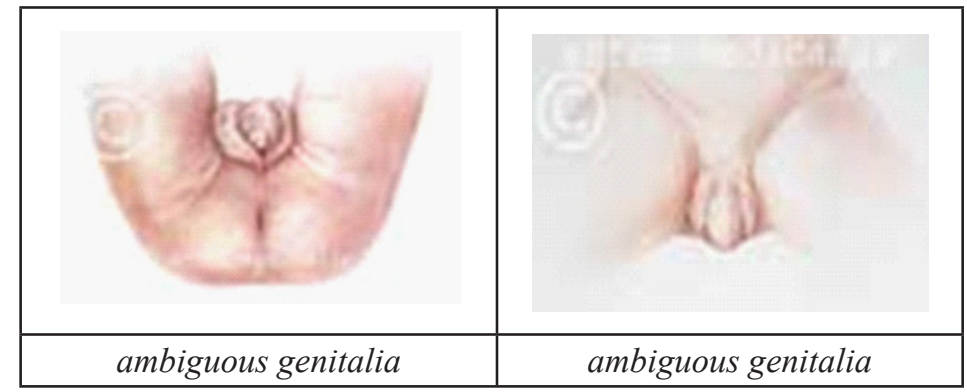

\footnotetext{
Ibid

8 http://www.artem-medicalis.com/clinical.htm, diakses pada 2 januari 2012.
} 


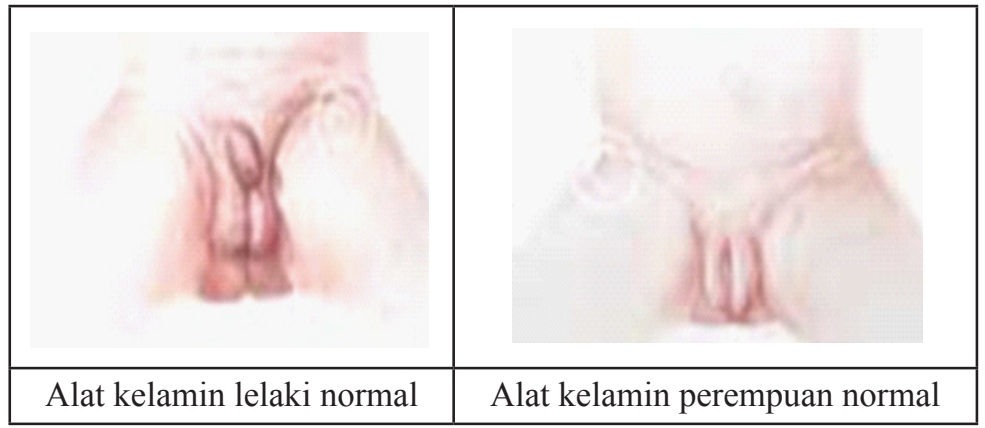

Rajah 2: Contoh kes ambiguous genetalia yang menunjukkan gambar alat kelamin yang mempunyai kedua-dua alat bagi lelaki dan perempuan ${ }^{9}$

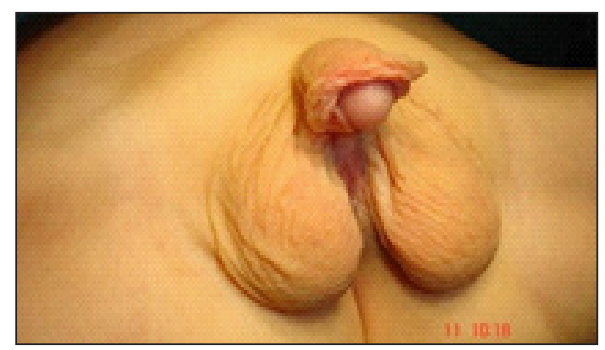

Dalam kes ambiguous genitalia, jantina bayi sukar ditentukan kerana terdapat kelainan alat kelamin atau rupa alat kelamin yang tidak sempurna. Kebanyakan pengidap ambiguous genitalia adalah individu yang sebenarnya mempunyai penyakit-penyakit tertentu seperti Congenital Adrenal Hyperplasia (CAH) dan Testicular Feminisation Syndrome (TFS).

9 http://www.isusemasa.com/2011/12/gambar-kemaluan-manusiakhunsa, diakses pada 2 Januari 2012. 


\section{Congenital Adrenal Hyperplasia $(\mathrm{CAH})^{10}$}

Penyakit ini hanya dimiliki oleh individu perempuan yang mempunyai lebihan hormon lelaki. Contohnya, terdapat bayi perempuan yang mengalami pembesaran klitoris yang sedikit dan ada pula klitoris membesar atau memanjang seperti kemaluan bayi lelaki. Kecelaruan jantina ini menimbulkan masalah untuk membuat catatan status jantina bayi dalam data atau sijil kelahiran mereka. Kesilapan pegawai perubatan mungkin menyebabkan kanak-kanak dibesarkan sebagai jantina yang bertentangan dengan kod genetik mereka.

Untuk mengelakkan situasi ini, pegawai perubatan perlu menangguhkan penentuan jantina bayi bagi membolehkan beberapa ujian dijalankan. Bayi ini biasanya akan dirujuk kepada pakar pediatrik dan endokrinologi untuk ujian dan rawatan lanjut. Selain ujian hormon, ujian genetik akan dijalankan untuk menentukan jantina bayi tersebut.

Lebihan hormon lelaki menyebabkan seseorang perempuan itu memiliki ciri-ciri lelaki seperti suara yang dalam, pertumbuhan bulu pada bahagian muka, tidak mengalami kedatangan haid serta alat kelamin yang lebih mirip kepada lelaki. Namun begitu, mereka masih memiliki organ pembiakan (ovari, uterus dan tiub fallopio) yang normal.

\section{Testicular Feminisation Syndrome (TFS) ${ }^{11}$}

Testicular Feminisation Syndrome (TFS) adalah sejenis penyakit yang dialami oleh seseorang yang memiliki kod genetik lelaki (satu kromosom $\mathrm{X}$ dan satu kromosom $\mathrm{Y}$ ) tetapi tisu-tisu yang membentuk organ pembiakan dan alat kelamin lelaki tidak bertindakbalas terhadap hormon lelaki. Ini disebabkan oleh kecacatan pada struktur kromosomnya. Jadi, individu ini mungkin memiliki semua atau sebahagian ciri-ciri fizikal perempuan,

10 Al-Mutair A, Iqbal MA, Sakati N, Ashwal A, "Cytogenetics and Etiology of Ambiguous Genitalia in 120 Pediatric Patients." U.S. National Library of Medicine, "Androgen Insensitivity Syndrome" http://www.nlm.nih.gov/medlineplus/ency/article/001180.htm, diakses pada 2 Januari 2012.

11 Olson GP, “Testicular Feminization Syndrome”, Nurse Pract 13 (2), Feb 1988, 27-32. 
walaupun secara genetiknya adalah lelaki. Oleh yang demikian, individu berkenaan pada zahirnya mempunyai alat kelamin seperti perempuan dan selalunya akan dibesarkan sebagai anak perempuan. Walau bagaimanapun, pada tahap sampai umur baligh (puberty), individu ini tidak mengalami kitaran haid disebabkan ketiadaan organ gonad dan sistem pembiakan perempuan seperti rahim (uterus), ovari dan tiub fallopio. Ujian genetik yang dilakukan akan mengesahkan kehadiran kromosom lelaki iaitu $\mathrm{XY}$ dan individu ini lebih selesa meneruskan hidup sebagai perempuan.

\section{KHUNTHA DARI PERSPEKTIF FIQH}

Tiada perbezaan yang ketara antara kriteria khuntha seperti yang dibincangkan oleh para ulama dalam kitab-kitab fiqh dan pakar perubatan terutama pandangan mengenai 'khuntha musykil' (hermaphrodite). Pendekatan yang digunapakai oleh ulama fiqh dalam menentukan ketidaktentuan jantina adalah lebih kepada tanda-tanda zahir yang ada pada seseorang. Penentuan jantina diukur dengan mengenalpasti salah satu alat kelamin yang lebih dominan berbanding yang satu lagi.

Walau bagaimanapun, pakar perubatan kini boleh membuat beberapa ujian bagi memastikan jantina bayi yang mengalami ketidaktentuan jantina.

Syaykh 'Ațiyyah Saqr, Ketua Lajnah Fatawa al-Azhar menyatakan bahawa bagi seorang lelaki, ada beberapa organ yang dianggap paling penting iaitu zakar, 'testes' dan yang berkaitan dengan kelelakian, seperti saluran mani dan prostat, serta menunjukkan tanda-tanda kelelakian apabila baligh; begitu juga bagi perempuan. Beliau membenarkan pertukaran jantina bagi khuntha, sebaliknya mengharamkan pertukaran jantina bagi mereka yang dilahirkan sebagai lelaki atau wanita tulen. ${ }^{12}$

Fuqaha mazhab Hanafi, Maliki dan Hanbali berpandangan, jika tumbuh janggut dan misai maka inidividu tersebut dikira lelaki manakala fuqaha mazhab Syafii pula berpendapat, ciri-ciri itu

12 Majma' al-Fiqh al-Islāmī (t. t.: Rābițah al-'Alamī) Fatwa 26 Februari 1989. 
belum cukup untuk membuktikan dia adalah lelaki tanpa disokong dengan tanda-tanda lain. Selain itu, fuqaha mazhab Hanafi dan Hanbali berpandangan, ciri-ciri wanita seperti pembesaran buah dada adalah tanda ia seorang wanita. Manakala fuqaha mazhab Syafii dan Hanbali berpendapat ciri-ciri itu mesti disokong oleh tanda-tanda kewanitaan yang lain. ${ }^{13}$

Bagaimanapun, berdasarkan penyelidikan dan perkembangan dunia perubatan, masalah ketidaktentuan jantina dapat diatasi sekiranya rawatan diberikan seawal mungkin iaitu sebelum usia 3 tahun. Kelewatan mendapatkan rawatan mungkin menjejaskan psikologi dan mendatangkan trauma kepada kanak-kanak. Persoalannya, mungkinkah pandangan mazhab Syafii dan Hanbali yang mensyaratkan tanda-tanda lain untuk menentukan jantina, termasuk tanda-tanda yang tersembunyi seperti lebihan hormon dan ujian genetik boleh diambil kira?

Tanpa menyebut hukum perkahwinan bagi golongan khuntha, Wahbah al-Zuhaylī mempunyai pandangan yang agak relevan. Menurut beliau, seseorang itu dianggap khuntha apabila jantinanya tidak diketahui sama ada lelaki atau perempuan. Cara untuk menentukan jantina menurutnya adalah melalui dari mana air kencing keluar. Selain itu, sifat zahir lelaki-perempuan seperti tumbuh janggut atau buah dada boleh menjadi petunjuk sama ada ia lelaki atau perempuan. Menariknya, Wahbah al-Zuhaylī mengemukakan pandangan bahawa perkembangan bidang perubatan melalui kajian membolehkan pembedahan dilakukan bagi menentukan jantina khuntha musykil..$^{14}$

Manakala Ibn Qudāmah dalam kitab al-Mughnī menyebut bahawa, penentuan jantina sama ada lelaki atau perempuan dapat dikenalpasti berdasarkan salah satu dari alat kelamin yang lebih dominan keluar air kencing. Jika alat kelamin lelaki lebih dominan bermakna ia adalah lelaki atau sebaliknya, dan seseorang itu tidak lagi dianggap musykil. Penentuan jantina khuntha musykil ini dapat ditentukan ketika sampai umur baligh iaitu individu yang mengalami haid dikira perempuan atau jelas ciri kelelakian seperti

13 Muḥammad Maḥy al-Dīn 'Abd al-Hāmid, al-Ahkām al-Mawārith fì Syarī'ah al-Islāmiyyah (t. t.: Dār al-Thalayk, t. t.), 1:201-202.

14 Wahbah al-Zuhaylī, al-Fiqh al-Islāmī wa Adillatu (Damsyiq: Dār alFikr, 1974), 10:7900. 
keinginan kepada wanita dan sebagainya maka dikira seorang lelaki. ${ }^{15}$

\section{PANDANGAN MUZAKARAH JAWATANKUASA FATWA KEBANGSAAN BAGI HAL EHWAL UGAMA ISLAM MALAYSIA (MJFK)}

Muzakarah Jawatankuasa Fatwa Majlis Kebangsaan Bagi Hal Ehwal Ugama Islam Malaysia Kali Ke-76 yang bersidang pada 2123 November 2006 telah membincangkan Isu Kecelaruan Jantina Congenital Adrenal Hyperplasia dan Testicular Feminization Syndrome. Muzakarah telah memutuskan bahawa: ${ }^{16}$

i) Bagi kes Congenital Adrenal Hyperplasia $(\mathrm{CAH})$ pembedahan jantina untuk kembali kepada genetik asal iaitu perempuan adalah diharuskan oleh Islam kerana ia boleh dilakukan melalui rawatan hormon dan pembedahan.

ii) Manakala bagi kes Testicular Feminization Syndrome (TFS) untuk kembali kepada genetik asal (lelaki) secara pembedahan atau rawatan hormon adalah sukar. Sekiranya individu berkenaan bercadang untuk melakukan pembedahan, ia adalah diharuskan selagi mana perbuatan tersebut tidak mendatangkan kemudharatan sama ada dari aspek psikologi atau biologi kepada individu tersebut.

iii) Bagikes Testicular Feminization Syndrome(TFS) yang dikesan ketika dewasa, individu tersebut boleh menjalani kehidupan seperti biasa dan jantina mereka diiktiraf berdasarkan fizikal dan genitalia zahir mereka. Pembedahan untuk mengeluarkan testes (sekiranya ada) adalah harus untuk mengelakkan risiko penyakit seperti mendapat kanser. Perkahwinan dengan pasangan mengalami Testicular Feminization Syndrome (TFS) tidak perlu dipisahkan.

15 Ibn Qudāmah, al-Mughn̄̄, 7:620; Ab̄̄ Zakariyyā Yaḥyā bin Syarīf al-Nawāwī, Rawụdah al-Ṭālibīn (Bayrūt: Dār al-Kitāb al-'Ilmiyyah, 2000), 1:188.

16 Keputusan Muzakarah Jawatankuasa Fatwa Majlis Kebangsaan Bagi Hal Ehwal Ugama Islam Malaysia (Jabatan Kemajuan Islam Malaysia (JAKIM), cet. ke-2, 2010), 74-75. 
iv) Pakar-pakar perubatan perlu memberi penjelasan, bimbingan dan menasihati ibu bapa serta individu-individu muslim yang terlibat dengan kes-kes Congenital Adrenal Hyperplasia (CAH) dan Testicular Feminization Syndrome (TFS) supaya menjalani rawatan bagi mengelakkan permasalahan hukum agama di kalangan umat Islam.

\section{PERLAKSANAAN IBADAH HAJI BAGI GOLONGAN KHUNTHA}

Jumhur fuqaha berpandangan bahawa hukum yang bersangkutan bagi khuntha dalam mengerjakan ibadah haji dan umrah adalah mengikut hukum sebagai seorang perempuan. ${ }^{17}$

Fuqaha mazhab Hanbali berpandangan bahawa seorang khuntha yang melakukan ihram adalah dibolehkan memakai pakaian berjahit dan tidak dikenakan fidyah ke atas dirinya sekiranya dia menutup kepala kerana dianggap sebagai perempuan. Demikian juga jika dia menutup mukanya dengan kain berjahit dan dia dianggap sebagai lelaki, maka dikenakan fidyah ke atasnya. ${ }^{18}$

Manakala Abū Yūsuf, fuqaha daripada kalangan mazhab Hanafi tidak dapat memberikan jawapan dalam isu ini kerana tidak diketahui kedudukan khuntha tersebut dari sudut jantinanya. ${ }^{19}$

Wahbah al-Zuhaylī menyatakan pandangan beliau dalam soal tawaf. Bagi kaum wanita dan golongan khuntha, mereka hendaklah bertawaf di hujung tepi kawasan tawaf. Bagaimanapun, sekiranya kawasan tawaf itu lengang daripada kaum lelaki, maka mereka juga digalakkan bertawaf berhampiran dengan Baitullah seperti orang lelaki. ${ }^{20}$

Fuqaha mazhab Syafii menjelaskan, sekiranya seorang khuntha sengaja menutup sama ada mukanya atau kepalanya sahaja, maka

\footnotetext{
17 Al-Mawsū'ah al-Fiqhiyyah (Kuwayt: Wizārah al-Awqāf wa alShu'ūn al-Islāmiyyah, 1989), 20:26

18 Ibid.

19 Ibid., 20:26.

20 Wahbah al-Zuhaylī, al-Fiqh al-Islāmī, 3:2227.
} 
dia tidak dikenakan fidyah. Tetapi jika dia menutup kedua-duanya sekali, maka dia wajib membayar fidyah. ${ }^{21}$

\section{MUKHANNATH}

Menurut penulis Qāmūs Mu'jam Lughat al-Fuqahà', almukhannath (المخنثت) bermaksud: lelaki yang menyerupai wanita dalam cara berjalan, bercakap, kemanjaan dan kelembutannya. ${ }^{22}$ Manakala Kamus Dewan menjelaskan laki-laki yang lebih bersifat perempuan atau perempuan yang bersifat kelaki-lakian dikenali sebagai pondan. ${ }^{23}$

Definisi Kamus Dewan ini seperti tidak membezakan antara perkataan 'pondan' untuk lelaki dan perempuan. Dalam masyarakat Melayu terdapat beberapa istilah yang digunakan untuk menggambarkan maksud lelaki yang bersifat keperempuanan seperti 'pondan', maknyah dan bapok. Manakala perempuan yang bersifat kelakian pula dipanggil sebagai pengkid.

\section{MUKHANNATH DARI PERSPEKTIF FIQH}

Menurut fuqaha mazhab Hanafi, jika mukhannath melakukan perbuatan keji, dia sama dengan lelaki, malah lebih dianggap fasik, dipisahkan dari kalangan wanita. Sekiranya kelembutan yang berlaku padanya adalah pembawaan semula jadi dan dia tiada syahwat terhadap wanita, tidak melakukan perbuatan keji, sesetengah masyaikh dalam kalangan Hanafiyyah merukhșahkannya berada bersama wanita. ${ }^{24}$

Mālikiyyah pula berpendapat mukhannath bukanlah yang terkenal dengan perbuatan keji dan dilabelkan dengan perbuatan tersebut, tetapi mukhannath ialah seorang yang sangat mirip kepada

21 Ibid., 3:2295-2296.

22 Muhammad Rawās Qalaj̄̄, Mu 'jam Lughat al-Fuqahā' (t. t.: Dār al Nafā'is, 1988), 1:417.

23 Kamus Dewan Edisi Baru (Kuala Lumpur: Dewan Bahasa dan Pustaka, 1991), 978.

24 Al-Sarkhas̄i Syams al-Dīn, Kitāb al-Mabsūṭ (Bayrūt: Dār al-Ma'rifah, 1993), 12:382; Ibn Nujaym al-Mișrī, al-Baḥr al-Rā'iq Syarh Kanz al-Daqā'iq (Bayrūt: Dār al-Ma'rifah, t. t.), 6:50. 
wanita pada asal kejadiannya, sehingga dia menyerupai wanita pada kelembutan gerak-geri, percakapan, pandangan, getaran suara, akal dan perbuatan, sama ada dia melakukan perbuatan keji atau tidak. Takhannuth pula ialah kecelaruan dan kelembutan. Jika individu mempunyai ciri seperti yang dinyatakan dan dia tiada keinginan kepada wanita, lemah akal, tidak celik terhadap urusan manusia dan bodoh, dia dianggap sebagai individu yang tiada keinginan kepada wanita yang dibolehkan bergaul dengan wanita. ${ }^{25}$

Syāfi'iyah berpendapat mukhannath ialah orang yang berakhlak dengan akhlak wanita dalam gerak-geri dan rupa diri dan jika itu merupakan pembawaan semulajadi, maka dia tidak berdosa. ${ }^{26}$

Hanābilah pula menjelaskan, mukhannath ialah mereka yang tiada syahwat. Hukumnya sama dengan keluarga mahram dalam kes memandang aurat silang jantina. Sekiranya dia ada syahwat dan celik wanita hukumnya adalah sama dengan hukum lelaki yang lain. ${ }^{27}$

Berdasarkan kenyataan di atas, jelas menunjukkan bahawa mukhannath terbahagi kepada dua iaitu:

Pertama: Mukhannath semula jadi iaitu lelaki yang berperawakkan wanita pada cara bercakap, kelembutan anggota dan kecelaruan kejadiannya. Dia tiada nafsu terhadap wanita, tidak dikenali dengan perbuatan keji. Dia tidak dianggap fasiq. Dia juga tidak termasuk dalam lingkungan mereka yang dilaknat dalam hadis-hadis Rasulullah SAW.

Kedua: Lelaki yang sengaja berperilaku sebagai perempuan dalam gerak-geri dan rupa diri (cara berpakaian, berhias dan perhiasan), menyerupai wanita pada rupa bentuk tubuhnya dan cara bercakap. Ia dianggap perbuatan buruk, maksiat dan pelakunya dianggap berdosa dan tergolong dalam mereka yang dilaknat. Berdasarkan kenyataan ini dapat disimpulkan bahawa jantina

${ }_{25}$ Ibn 'Abd al-Bārī, al-Tamhīd Limā fì al-Muwatțā' min al-Ma 'ān̄̄ wa al-Asānid (Maktabah al-Madīnah al-Raqmiyyah, t. t.), 22:273.

26 Al-Syarbīn̄̄ Muhammad al-Khāțib, Mughn̄̄ al-Muhtāj ilā Ma rifat Alfāz al-Minhāj (Bayrūt: Dār al-Fikr, t. t.), 4:430.

27 Ibn Qudāmah, al-Mughnī, 7:462. 
mukhannath jenis kedua ini adalah lelaki. Penentuan ini didasarkan kepada:

i. Kaedah fiqhiyyah: Kقاء ما كان على ما كان الأصل

Mengekalkan hukum berdasarkan asal sesuatu. Syariat Islam sentiasa dibina di atas الأغلبية (kebiasaan umum). Lelaki yang sengaja berperilaku sebagai perempuan dalam gerak-geri dan rupa diri pada hakikat dan asalnya adalah lelaki. Oleh itu, hukum adalah dikembalikan kepada asal lelaki.

ii. Kes ini termasuk kes terpencil شاذ. Kes-kes syādh tidak boleh dijadikan asas pembinaan hukum. Kaedah-kaedah berkaitan ialah:
a. الشاذ لا يقاس عليه
b. النادر لا حكم عليه

Dalam kes ini, perbuatan lelaki yang sengaja berperilaku sebagai perempuan dalam gerak-geri dan rupa diri adalah ganjil dan jarang berlaku dalam masyarakat. Ia bukan keadaan biasa. Oleh yang demikian, keadaan ganjil dan bukan kebiasaan dalam masyarakat tidak boleh dijadikan sebagai asas penentuan hukum.

iii. Orang awam yang normal dalam masyarakat dapat membezakan antara lelaki dan perempuan. Ulama juga telah menjelaskan hukum berkaitan mereka. Penelitian ilmiah telah dapat menjelaskan pelbagai hakikat mukhannath jenis pertama. Berdasarkan penjelasan ini, pelbagai hukum berkaitan mereka telah ditentukan. Yang masih belum jelas ialah kes mereka yang sengaja menjadi mukhannath.

\section{MUKHANNATH DAN PERTUKARAN JANTINA}

Menukar jantina adalah satu perbuatan yang haram sekiranya dilakukan tanpa sebab yang kukuh kerana telah mengubah ciptaan Allah SWT. Perkara ini telah difatwakan oleh Muzakarah Jawatankuasa Fatwa Majlis Kebangsaan Bagi Hal Ehwal Ugama 
Islam Malaysia (MJFK) Kali Ke-4 yang bersidang pada 13-14 April 1982 seperti yang berikut: ${ }^{28}$

i) Pertukaran jantina dari lelaki kepada perempuan atau sebaliknya melalui pembedahan adalah haram dari segi syarak.

ii) Seseorang yang dilahirkan lelaki, hukumnya tetap lelaki walaupun ia berjaya ditukarkan jantinanya melalui pembedahan.

iii) Seseorang yang dilahirkan perempuan, hukumnya tetap perempuan walaupun ia berjaya ditukarkan jantinanya melalui pembedahan.

iv) Seseorang yang dilahirkan khuntha musykil iaitu manusia yang dilahirkan mempunyai dua alat kemaluan lelaki dan perempuan, diharuskan pembedahan bagi mengekalkan salah satu alat jantina yang benar-benar berfungsi dapat digunakan mengikut keadaan yang sesuai.

\section{IBADAT HAJI MUKHANNATH}

Oleh kerana mukhannas, sama ada yang semulajadi atau yang disengajakan pada hakikatnya adalah lelaki, maka hukum ibadat hajinya adalah hukum ibadat haji lelaki dalam semua perkara. Begitupun, adalah dibolehkan sekiranya ada keperluan untuk menempatkan mukhannath semulajadi yang tiada syahwat terhadap perempuan di tempat yang sama dengan wanita. Ini didasarkan kepada pendapat fuqaha yang memberikan keringanan kepada mukhannath kategori ini bergaul dengan wanita. Namun bagi mereka yang sengaja menjadi mukhannath sama ada telah menukar jantina atau tidak, tidak boleh ditempatkan bersama dengan wanita.

\section{KESIMPULAN}

Khuntha atau dalam erti kata kecelaruan jantina pada diri seseorang individu dalam permasalahan ibadat sama ada ibadat

28 Keputusan Fatwa Kebangsaan Siri 1 (Jabatan Kemajuan Islam Malaysia (JAKIM), cet. ke-2, 2007), 10-11. 
fardu, wajib ataupun sunat, hendaklah merujuk kepada genetalia yang zahir (alat kelamin). Ini terpulang kepada seseorang individu untuk menentukan kedudukannya kerana perkara ini adalah sulit dan sukar ditentukan oleh orang lain.

Sekiranya dia mempunyai ciri-ciri luaran atau fizikal seorang perempuan dan boleh menjalani kehidupan sebagai perempuan, malah boleh berumahtangga, walaupun dari segi perubatan mereka dianggap 'lelaki' (XY), maka ciri-ciri luaran tersebut adalah lebih kuat mempengaruhinya sebagai seorang perempuan. Ini sebagaimana yang diputuskan oleh MJFK kali ke-76 tentang testicular feminization syndrome (TFS).

Begitu juga, jika sekiranya seseorang itu mempunyai ciri-ciri luaran atau fizikal seorang lelaki, tetapi dari segi perubatan dia dianggap 'perempuan' (XX), maka ciri luaran atau fizikal tersebut adalah lebih kuat untuk dia cenderung ke arah lelaki.

Jumhur fuqaha berpandangan bahawa hukum yang bersangkutan bagi khuntha dalam mengerjakan ibadah haji dan umrah adalah mengikut hukum sebagai seorang perempuan. Manakala, bagi mukhannath, semulajadi atau yang disengajakan, sama ada telah melakukan pembedahan menukar jantina atau tidak atau menukar jantina dengan melakukan pembedahan bukan disebabkan keharusan syarak, maka hukum dalam menjalankan ibadat bagi individu tersebut termasuk ibadat haji dan umrah hendaklah mengikut hukum asal kejadian dirinya.

\section{BIBLIOGRAFI}

Al-Bustan̄̄, Fu'ād Ifram. Munjib al-Ṭullab. Bayrut: Dar alMusyriq, t. t.

Al-Mawsū'ah al-Fiqhiyyah. Kuwayt: Wizārah al-Awqāf wa alSyu'ūn al-Islāmiyyah, 1989.

Al-Mișrī, Ibn Nujaym. Al-Baḥr al-Rā'iq Syarh Kanz al-Daqā'iq. Bayrūt: Dār al-Ma'rifah, t. t.

Al-Mutair A, Iqbal MA, Sakati N, Ashwal A, "Cytogenetics And Etiology Of Ambiguous Genitalia in 120 Pediatric Patients" Ann Saudi Med. Sep-Oct 2004, 24(5):368-72.

Al-Nawawī, Abī Zakariyyā Yaḥyā bin Syarif. Rawḍh al-Ṭālibīn. 
Bayrūt: Dār al-Kitāb al-'Ilmiyyah, 2000.

Al-Sarkhas̄î, Syams al-Dīn. Kitāb al-Mabsūt. Bayrūt: Dār alMa'rifah, 1993.

Al-Syarbīn̄i, Muhammad al-Khāțib. Mughnī al-Muhtāj ilā Ma 'rifat Alfāz al-Minhāj. Bayrūt: Dār al-Fikr, t. t.

Al-Zuhaylī, Wahbah. Al-Fiqh al-Islāmī wa Adillatuh. Damsyiq: Dār al-Fikr, 1997.

http://www.artem-medicalis.com/clinical.htm. Diakses pada 2 januari 2012.

http://www.isusemasa.com/2011/12/gambar-kemaluan-manusiakhunsa. Diakses pada 2 Januari 2012.

Kamus Dewan Edisi Empat. Kuala Lumpur: Dewan Bahasa dan Pustaka, 2007.

Keputusan Muzakarah Jawatankuasa Fatwa Majlis Kebangsaan Bagi Hal Ehwal Ugama Islam Malaysia. (JAKIM), cet. ke-2, 2010.

Ibn 'Abd al-Bārī. Al-Tamhìd Limā fì al-Muwațtā' min al-Ma 'ān̄̄ wa al-Asānid. Maktabah al-Madīnah al-Raqmiyyah, t. t.

Ibn Qudāmah. Al-Mughnī wa al-Syarḥ al-Kabīr. t. t.: Dār al-Kitāb al-'Arabīi, t. t.

Majma' al-Fiqh al-Islāmī (t. t.: Rābițah al-'Alamī) Fatwa 26 Februari 1989.

Muhammad Maḥy al-Dīn 'Abd al-Hāmid. Al-Ahkām al-Mawā' rith fì Syarī'ah al-Islā'miyyah. t. t.: Dār al-Thalayk, t. t.

Muhammad Rawas Qalaji. Mu'jam Lughat al-Fuqahā'. t. t.: Dār al-Nafâ'is, 1988.

Olson GP. "Testicular Feminization Syndrome." Nurse Pract. Feb;13(2), 1988.

Timothy G. Canty. "The Child with Ambiguous Genitalia: A Neonatal Surgical Emergency.” In Ann Surg 186 (3) 1977, 272-279.

U.S. National Library of Medicine. "Ambiguous Genitalia." http://www.nlm.nih.gov/medlineplus/ency/article/003269. htm. Diakses pada 2 Januari 2012. 